\title{
Guest Editorial: Vulnerability Revisited
}

\author{
DORIS SCHROEDER and GARDAR ARNASON
}

In Jane Austen's Mansfield Park (1814), Fanny, an 18-year-old orphan who lives with her aunt Lady Bertram, received an attractive offer of marriage, which she vehemently rejected and is not prepared to reconsider.

\begin{abstract}
Lady Bertram ... had been a beauty ... all her life; and beauty and wealth were all that excited her respect. To know Fanny to be sought in marriage by a man of fortune raised her... very much in her opinion.... "Well, Fanny, I have had a very agreeable surprise this morning. I must just speak of it once... . I give you joy [i.e., congratulations], my dear niece." ... Fanny coloured, and doubted at first what to say; when, hoping to assail her on her vulnerable side, she presently answered-“"My dear aunt, you cannot wish me to do differently from what I have done, I am sure. You cannot wish me to marry; for you would miss me, should not you?"1
\end{abstract}

Those who have read the entire book will know that Fanny is not interested in whether her aunt would miss her or not. She targeted what she perceived as her aunt's vulnerable side-her wish for a companion to avoid loneliness-and manipulated it to serve her own interests, namely, not to have to marry a particular suitor. Her aunt cannot protect herself against this manipulation because she is unaware of it. Had another gentleman proposed, Fanny would have accepted immediately with no regard for her aunt's wishes for a companion. She thereby tried to instrumentalize her aunt to achieve her own goal, namely, not to marry this suitor. Yet, most readers are favorably inclined toward Fanny. Why is this so? The aunt will not be harmed if Fanny stays with her, either emotionally or physically. By contrast, Fanny is in a highly vulnerable position and could easily be harmed through a marriage to a suitor she despises. And, as an orphan, she has very few means to defend herself against the proposal. Readers are therefore inclined to accept her attempt at exploiting her aunt's vulnerability, as her own is much greater and she does not intend to create harm.

Anecdotally, this short scene from Mansfield Park illustrates only some of the difficulties and pitfalls one can encounter when discussing vulnerability. What exactly is it? How does it relate to harm? Which harms are the vulnerable facing? How can the vulnerable be protected from harm? Can the vulnerable be identified according to group characteristics? How can they be empowered?

The following papers attempt to bring more clarity to vulnerability within the medical context, show how it relates to issues of harm, inducement, and gender, and put it to the test by applying it to two actual cases of potentially vulnerable groups.

Given recurrent complaints about the concept's vagueness, Doris Schroeder and Eugenijus Gefenas develop a definition of vulnerability in the context of 


\section{Guest Editorial}

medical research. The authors then argue that vulnerability of research subjects should be assessed in terms of identifiable markers for significant harms as opposed to universal classifications.

Discussions of vulnerability of research subjects and the possibility of exploitation often involve a concern termed "undue inducement." The concern is that providing any benefits to poor or vulnerable research subjects, whether in the form of monetary payments, access to healthcare and medications, or any other form, may unduly influence the subject's decision to participate in research. Gardar Arnason and Anton van Niekerk argue that this concern is misplaced and that the fear of undue inducements should not prevent providing benefits to vulnerable research subjects.

Fatima Alvarez-Castillo, Julie Cook Lucas, and Rosa Cordillera Castillo investigate the importance of gender as a factor in vulnerability and its intricate relations to other vulnerability factors. They argue that in the light of gender issues, special care must be taken to ensure justice, and hence avoid exploitation, when women in developing countries participate in research. They also emphasize that self-recognition of vulnerability can be the first step toward empowerment.

The final two papers look at the issue of vulnerability in very specific and real circumstances. Pamela Andanda discusses research participation of sex workers in Nairobi's Majengo slum. Because of their profession and the fact that they are educationally and economically disadvantaged, these women present a powerful example of vulnerability-but also of strength. Andanda applies the concept of vulnerability defined by Schroeder and Gefenas to this case. She also provides an insight into the views and concerns of the women with regard to participating in research and shows how vulnerability in this case may raise concerns about undue inducements and the sharing of benefits.

The special section concludes with Roger Chennells' study of vulnerability and potential exploitation in the context of the commercial use of traditional knowledge of the San people of Southern Africa. Applying the definition of vulnerability presented by Schroeder and Gefenas, Chennells shows how the collective vulnerability of the San has developed through their harsh history and provides suggestions about how such vulnerability may be limited in the future.

As a set, the papers offer a new understanding of vulnerability, both conceptually and in terms of its importance in the context of real, vulnerable people.

\section{Note}

1. Austen J. Mansfield Park. Cambridge, UK: Cambridge University Press; 1814, 2005:384. 